\title{
Universal equipment for determining traction resistance of working bodies and their combinations designed for soil treatment
}

\author{
Maxim P. Erzamaev ${ }^{1, *}$, Dmitry S. Sazonov ${ }^{1}$, Alexander E. Afonin ${ }^{1}$, Leila S. Kurmanova ${ }^{2}$, and Evgeny S. Nesterov ${ }^{3}$ \\ ${ }^{1}$ Samara State Agrarian University, Samara, 446442, Russia \\ ${ }^{2}$ Samara State Transport University, Samara, 443066, Russia \\ ${ }^{3}$ Saratov State Agrarian University n.a. N. I. Vavilov, Saratov, 410012, Russia
}

\begin{abstract}
The article describes a strain gauge measuring system designed for measuring the traction resistance of tillage bodies and their combinations. Technical tools measure the traction resistance of the whole machine or one working body which is not an objective and reliable characteristics of combined tillage units. The design and principle of operation of the tensometric measuring system designed and manufactured by Samara State Agrarian University is described. It is used to determine the traction resistance of individual working bodies and their combinations. The results show that the measurement data on traction resistance are in compliance with the calculated values.
\end{abstract}

\section{Introduction}

A steady trend in the development of modern machine designs and tillage technologies is a combination of several different technological processes of tillage (loosening, crumbling, mixing or changing the vertical position of its layers, surface alignment, soil compaction, etc.) $[1,2]$. In addition, combinations of tillage equipment and sowing and planting units are used [3,4].

This trend is due to the prospect of reducing the harmful compaction effect of tractor movers on the soil by reducing the number of passes, as well as lowering the labor costs of MTU operators.

Important features of the soil treatment using combined machines is the mutual influence of combination elements, for example, the imposition of soil deformation zones, the need to coordinate the paths of movement of soil particles, etc. These features affect quality indicators and energy parameters of the MTU.

\section{Materials and methods}

When creating and updating tillage machines, one of the most important energy evaluation parameters is their traction resistance determined by the dynamometry using tensometric devices [5-9]. Technical tools measure the traction resistance of the whole machine or one working body which is not an objective and reliable characteristics of combined tillage units. [3, 10, 11].

Therefore, assessment of the traction resistance of the working body and creation of real working conditions (loosening, compaction, removal of the soil layer, furrow formation, etc.) taking into account the influence of other combined working bodies is required to optimize the parameters of mutual alignment in the horizontal plane and along vertical combinations of the soil cultivating working bodies, as well as their structural parameters.

In Samara State Agrarian University, a tensometric measuring system was designed and manufactured. It is used to determine the traction resistance of both individual working bodies and their combinations. The system consists of a strain gauge unit (Figure 1, 1) aggregated with tractors of traction class 5, and an information-measuring system (Figure 3,4).

The strain gauge unit (Figure 1) consists of supporting frame 1 and movable frame 2 which are interconnected by bearing units 3 , forming a parallelogram mechanism (Figure 2a). Hinged device 6 and two support wheels 7 with mechanisms for changing the working depth 8 are fixed on a supporting frame (Figure 1), consisting of transverse beam 4 and longitudinal beams 5 . The movable frame consists of transverse beam 9 and longitudinal beams 10 fastened with bolted joints. To relieve the force of traction resistance of the working bodies between the movable and non-movable parts of the frame, strain gauge $\mathrm{S}$-shaped compression-tension sensor 11 is designed for a force of up to $50 \mathrm{kN}$. In this case, the movement of the movable (lower) frame is limited by a strain gauge $\mathrm{S}$ shaped sensor (Figure 2 b.).

The working bodies 12 (Figure 1) are installed in brackets, fixed with brackets and threaded joints on transverse beam 4 of the upper part of the frame and movable transverse bars 13 and 14. Transverse beam 13 is attached to longitudinal beam 10 with brackets, platforms and threaded joints parts of the frame.

*Corresponding author: Erzamaev_MP@mail.ru 
Transverse beam 14 is attached to longitudinal beam 5 of the upper part of the frame or to longitudinal beam 10 of the lower part of the frame using brackets, platforms and threaded connections.

The mounting feature of movable transverse bars 13 and 14 helps install them in the same plane with transverse beam 4 of the fixed part of the frame. This is required when placing the working bodies in several rows in order to fix the working body on beam 13 of movable frame 2 as close as possible to the real conditions.

To determine an actual treatment depth, a gauge for measuring a depth of working body 15 is attached to transverse beam 14 using brackets, pads and threaded joints.

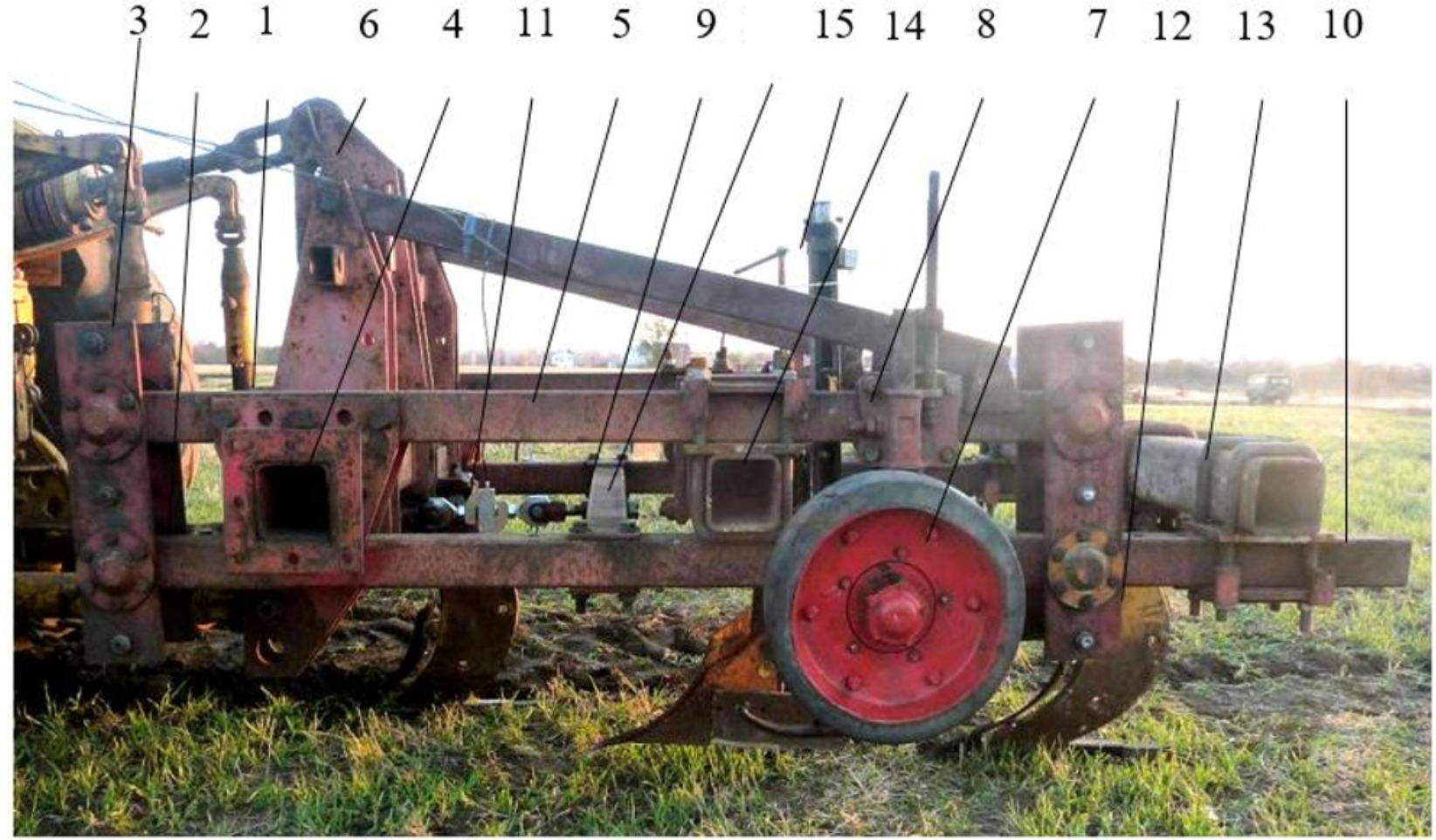

Fig. 1. The strain gauge unit: 1 - supporting frame; 2 - movable frame; 3 - bearing assembly; 4 - transverse beam; 5 - longitudinal bar; 6 - attachment; 7 - basic wheel; 8 - mechanism for changing a depth; 9 - transverse beam; 10 - longitudinal bar; 11 - strain gauge S-shaped compression-tension sensor $\mathrm{C} 2 \mathrm{H} ; 12$ - working body; 13 - movable transverse beam; 14 - movable transverse beam; 15 measuring unit for a depth of the working body; 16 - adjusting screw.
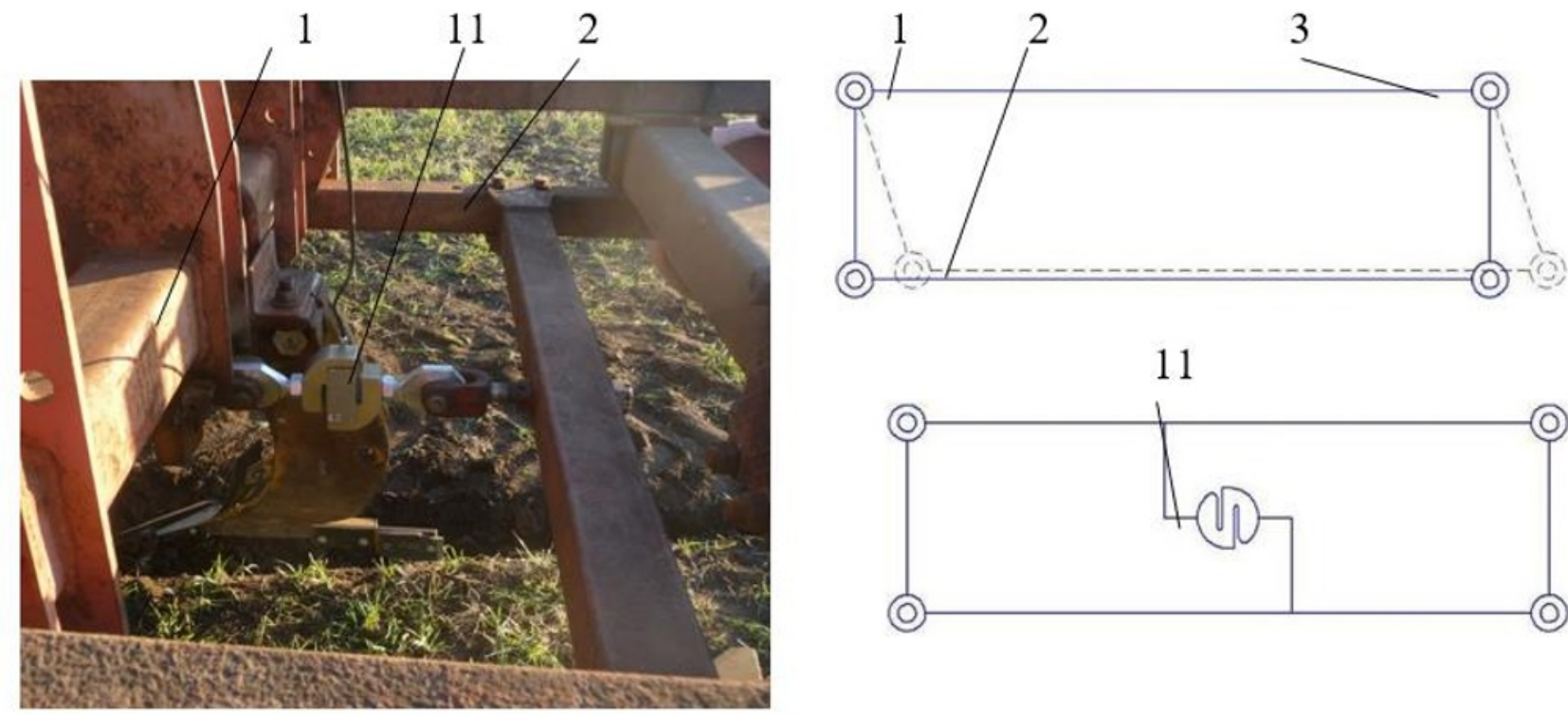

11

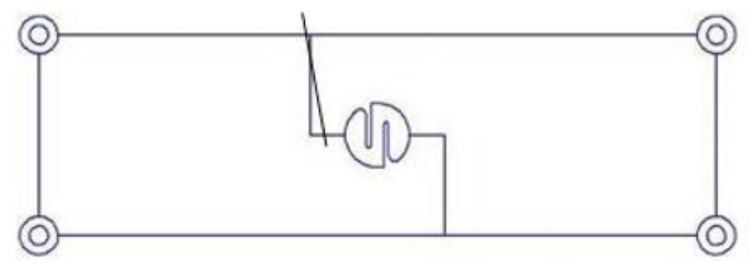

Fig. 2. A parallelogram mechanism of the strain gauge unit. 


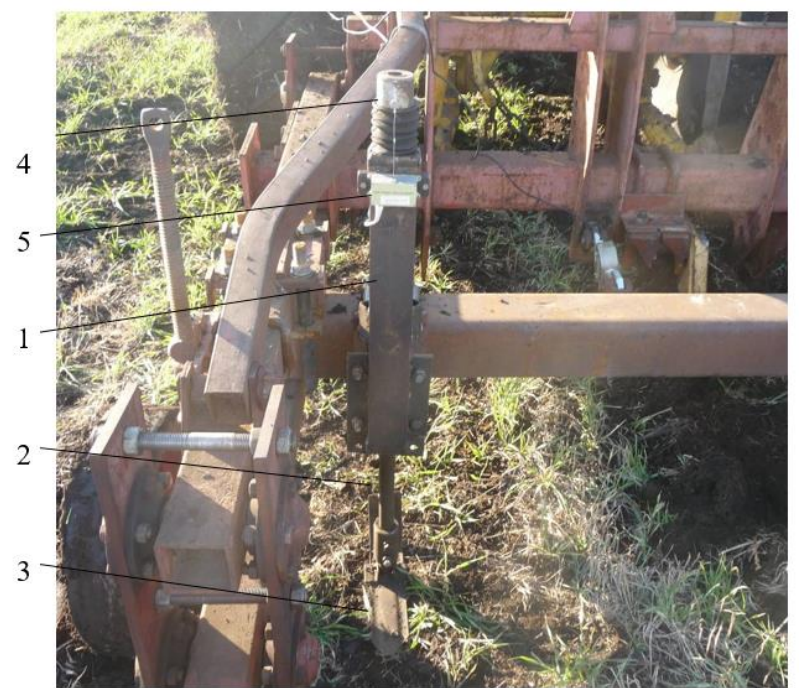

Fig. 3. A gauge measuring a depth of the working body: 1 case; 2 - core; 3 - ski; 4 - string; 5 - linear displacement sensor VT-718.

The depth measuring gauge of the working body (Figure 3) consists of housing 1, inside which rod 2 moves on the bearings. To copy the surface of the field, ski 3 is fixed on the lower part of the rod. The value of the rod displacement with string 4 is transmitted to linear displacement sensor 5 .

The information-measuring system (Figures 4, 5) includes strain gauge sensor 1 and linear displacement sensor 2. Their signals are transmitted to analog-to-digital converter 3 .

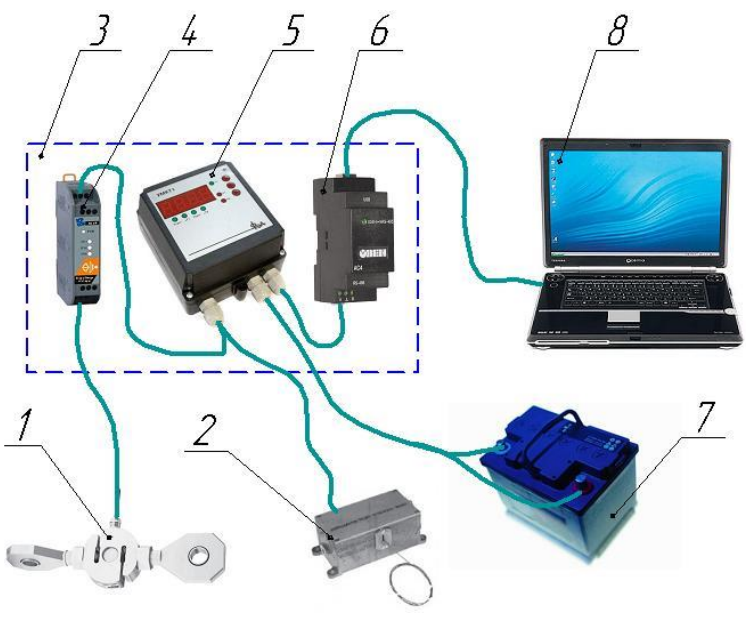

Fig. 4. The information-measuring system: 1 - strain gauge Sshaped compression-extension sensor $\mathrm{C} 2 \mathrm{H} ; 2$ - linear displacement sensor VT-718; 3 - analog-to-digital converter; 4 - signal normalizer strain gauge SG-3016; 5 - signal meter UMKT2; 6 - interface converter Aries AC4; 7 - rechargeable battery $6 \mathrm{CT}-60 ; 8$ - personal computer.

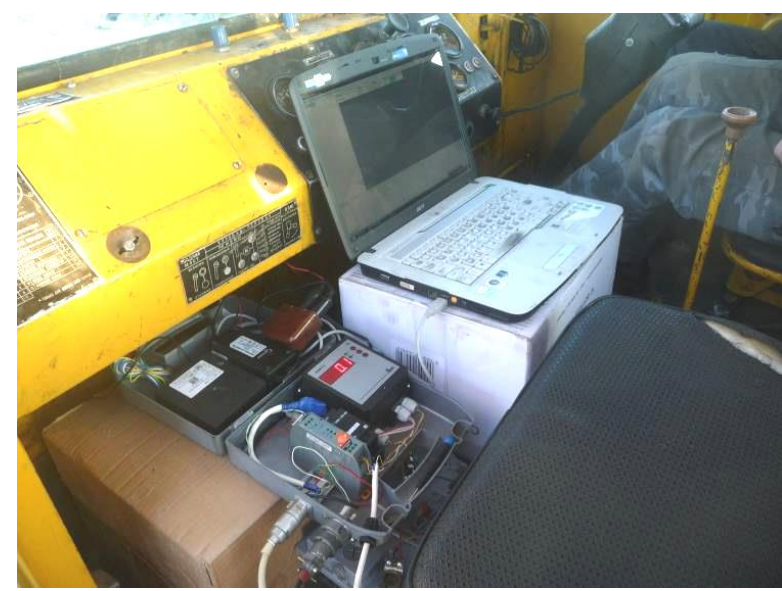

Fig. 5. The information-measuring system

The analog-to-digital converter consists of a signal normalizer of strain gauge 4 , signal meter 5 and interface converter 6 (Figure 4).

In the analog-to-digital converter, the signals are amplified (by a signal normalizer), recognized (by a signal meter), converted (by an interface converter) for subsequent transmission to a personal computer and processed in GAUS 8.

GAUS 8 was developed by the FEA LLC company for bringing all the data from sensors and devices into a single network and displaying them on the operator's personal computer in real time [6]. GAUS 8 collects information from sensors connected to the system, archives sensor readings, outputs sensor readings in tabular and graphical forms (Figure 6).

GAUS 8 records the time and force values for the working body and actual tillage depths.

Before taking measurements, the measuring unit is calibrated. The strain gauge unit rises so that the working bodies do not touch the soil surface, and the installation frame is in a horizontal plane. Sensor 11 (Figure 1) is disconnected from the strain gauge unit. Turning the adjusting screw "zero" of signal normalizer 4 (Figure 4), value " 0 " is set on the indicator of signal meter 5 . The strain gauge sensor is installed on the strain gauge unit; using adjusting screw 16 (Figure 1), we can obtain value " 0 " on the indicator of signal meter 5 (Figure 4).

Results of the studies on traction resistance of plow working bodies and their combinations can be illustrated with some examples. For mounting the working bodies on the strain gauge unit, brackets were produced.

The energy assessment was carried out on a $100 \mathrm{~m}$ field plot. The strain gauge unit was aggregated with a $\mathrm{K}$ 701 tractor. The experiments were carried out at a speed of 1.5 to $2.5 \mathrm{~m} / \mathrm{s}$. To ensure a constant working width of the working body, a ripper was placed on the strain gauge simulating the passage of the previous working body, ensuring the required working width, and eliminating the blocked cutting by the working body. To determine the traction resistance, a non-dump plow body was designed. 


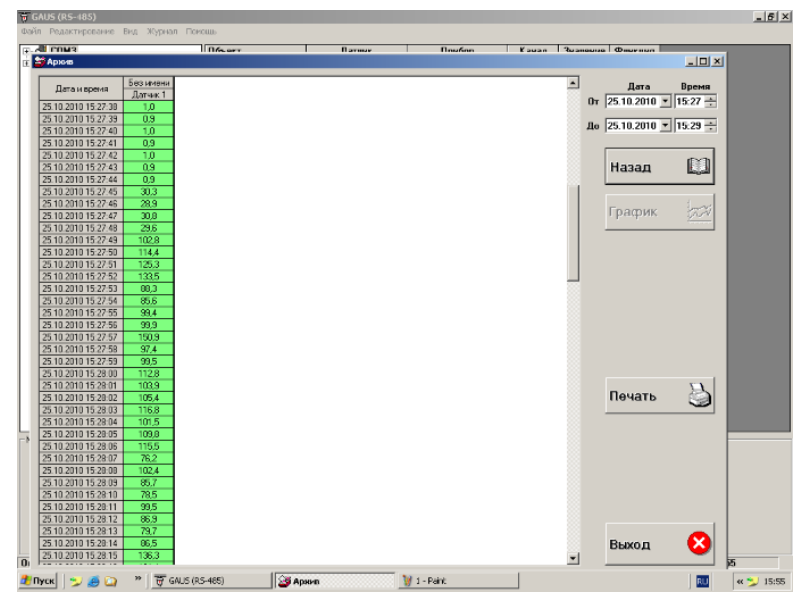

a)

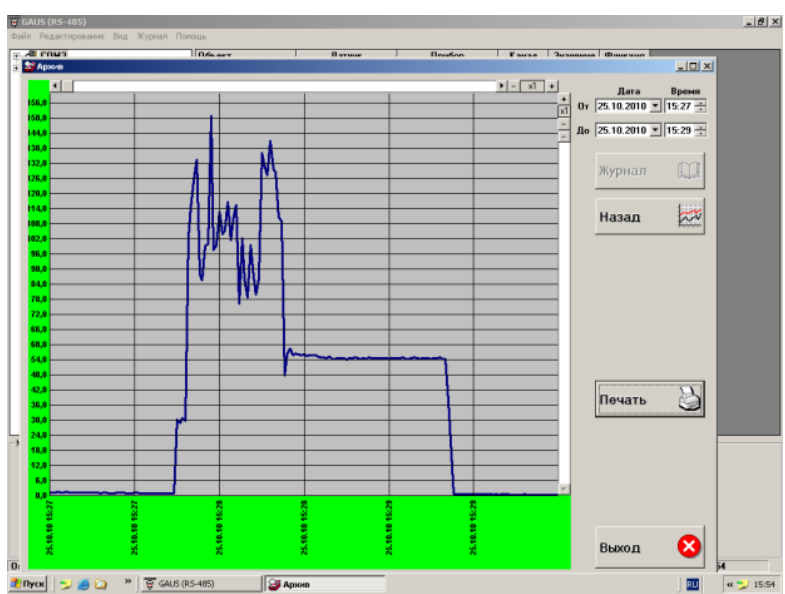

b)

Fig. 6. The GAUS window: a) - archived data in the tabular form; b) - archived data in the graphic form

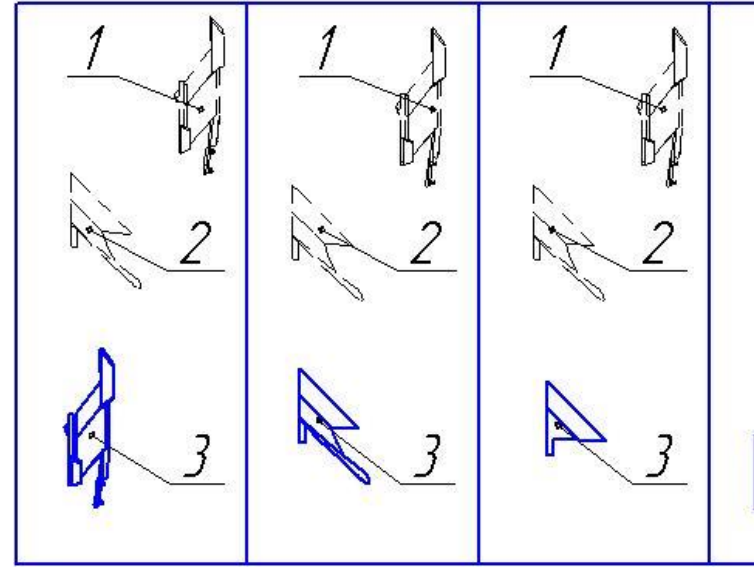

a) b) c)

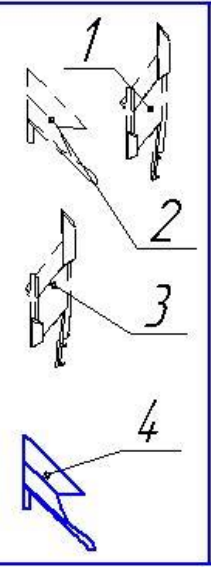

d)

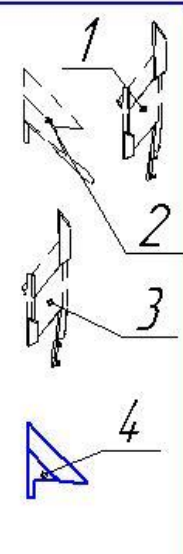

e)

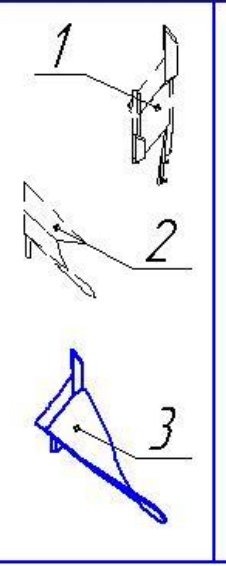

f)

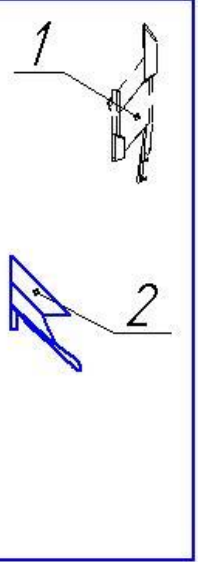

g)
Fig. 7. Options for arranging combinations of working bodies

The experiments were conducted with the following installation options (Figure 7):

a) Determination of the change in traction resistance of the cultivator depending on the thickness of the removed topsoil. Control cultivator 1; ploughshare-dump body of the upper tier 2 with a ploughshare and a dump for removing the top soil; cultivator 3 fixed on the tensometric (movable) part of the frame are located on the strain gauge unit (Figure 7). The experiment was conducted by installing a plow body of the upper tier to a depth of $0.06 ; 0.12 ; 0.18 ; 0.24 ; 0.30 \mathrm{~m}$. Rippers 1 and 3 were installed at a depth of $0.45 \mathrm{~m}$.

b) Determination of traction resistance of the plow body of the lower tier without dumping in loose soil. Control ripper 1, ploughshare-dump body of the upper tier 2 , ripper 3 , plow body without blades 4 fixed on the tensometric (movable) part of the frame are located on the strain gauge unit. The experiment was conducted by installing plow body of the upper tier 2 to a depth of 0.12 $\mathrm{m}$, cultivator 3 - to a depth of $0.45 \mathrm{~m}$, plow body without blades 4 - to a depth of $0.30 \mathrm{~m}$.

c) Determination of traction resistance of the shellless ripping plow body of the lower tier. Control ripper 1, ploughshare-dump body of the upper tier 2; loosening body of the lower tier 3 fixed on the tensometric (moving) part of the frame are located on the strain gauge unit. The experiment was conducted by installing plow body of the upper tier 2 to a depth of $0.12 \mathrm{~m}$, plow body of the lower tier 3 - to a depth of $0.45 \mathrm{~m}$.

d) Determination of traction resistance of the plow body of the upper tier. Control ripper 1 was used to ensure a constant distance from the measured working body to the furrow edge; ploughshare-dump body of the upper tier 2 was fixed on the tensometric (movable) part of the frame. The experiment was conducted by installing plow body of the upper tier 2 at a depth of $0.6 ; 0.12 ; 0.18 ; 0.24$ $\mathrm{m}$.

The depth of installation of the cultivator was $0.45 \mathrm{~m}$. The width of the plow bodies was $0.45 \mathrm{~m}$.

To exclude the effect of soil compaction, the working bodies were installed outside wheel tracks.

The passage time was recorded by a stopwatch. The data were recorded in the research protocol. After the statistical processing, graphical changes in traction were built depending on the factors considered. 


\section{Results}

Figure 8 shows the dependence of traction resistance of the sections of the working bodies determined by the calculated and experimental methods.

Reliability of the measurement results is confirmed by the calculated values $[12,13]$; when checking the correspondence between experimental and theoretical distributions of parameter values according to criterion $\chi^{2}$ with a reliability of the results equal to $95 \%$, the obtained value $\chi^{2}$ is less than the table value $\left(\chi_{\text {fact }}^{2}<\chi^{2}{ }_{05}\right)$.

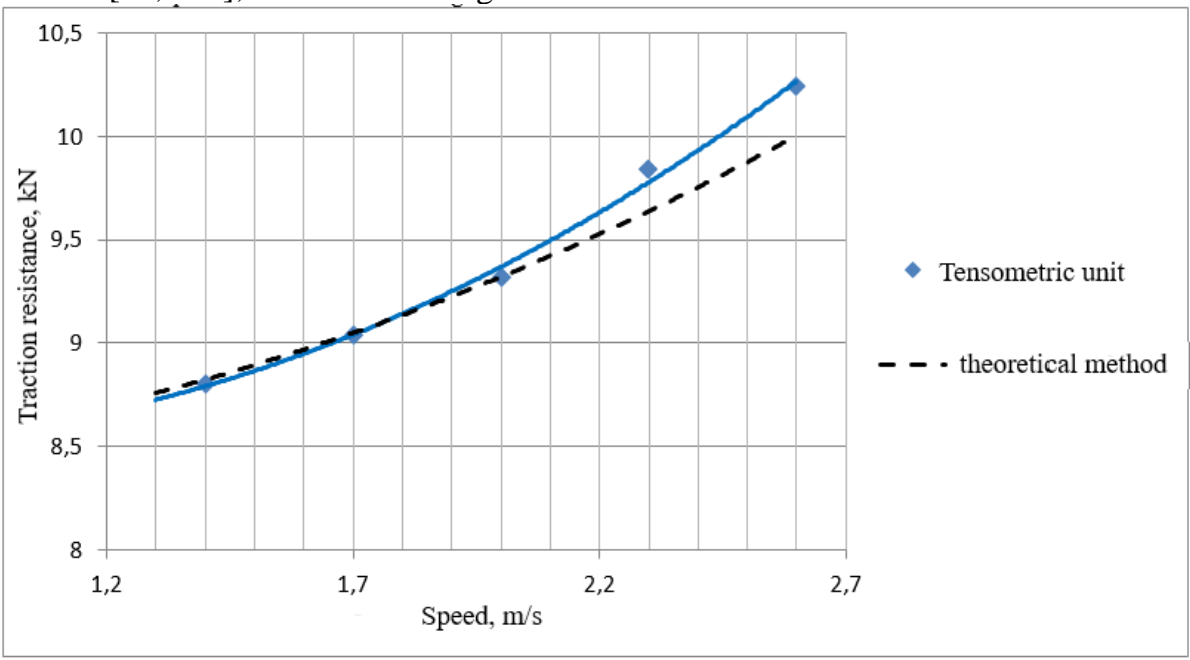

Fig. 8. The dependence of traction resistance of working body sections on speed during the longline tillage

\section{Conclusion}

Thus, the universal equipment designed by Samara State Agrarian University for studying the traction resistance of tillage working bodies and their combinations can be widely used when creating and improving the design of combined tillage machines.

\section{References}

1. V.M. Boykov, E.S. Nesterov, Moisture-saving method of the main tillage Bulletin of Saratov State Agrarian University named after N.I. Vavilov 12, 49-50 (2010)

2. E.S. Nesterov, The results of the study of a PBC-4.8Ch soil treatment tool Bulletin of Saratov State Agrarian University n.a. N.I. Vavilov 1, 48-50 (2011)

3. T. Machado, K. Lanças, Prototype for soil mechanical resistance measurement with chisel plow automated control Engenharia Agrícola 36, 646-655 (2016)

4. J. Musil, J. Červinka, Měrení tahového odporu strojů $S$ pasivními pracovními orgány Res. Agr. Eng. 53, 4753 (2007)

5. M. N. Lysych, M.L. Shabanov, P.V. Zakharov, A review of the designs of strain gauges for studying power parameters of the working bodies of tillage tools Modern problems of science and education 1 (2015) Retrieved from: www.scienceeducation.ru/121-17126

6. V. A. Drobot, B. F. Tarasenko, New field installation for engineering evaluation of tillage working bodies Scientific J. of KubSAU, 91 (2013) Retrieved from: https://cyberleninka.ru/article/n/novaya-polevayaustanovka-dlya-inzhenernoy-otsenkipochvoobrabatyvayuschih-rabochih-organov

7. A. Rucins, A. Vilde, Research for rural development 2003. Int. scientific conf. proc. Jelgava, Latvia 21-24 May, 2003, 64-67 (Jelgava, Latvia University of agriculture, 2003)

8. A. Rucins, A. Vilde, Research for rural development 2003. Int. scientific conf. proc. Jelgava, Latvia 21 24 May, 2003, 61-63 (Jelgava, Latvia University of Agriculture, 2003)

9. V.M. Boykov, E.S. Nesterov, S.V. Startsev, K.K. Okas, Traction resistance of the chisel working body Scientific Review 5, 72-77 (2017)

10. L. Vlăduțoiu, A. Tudor, V. Vladut, C. Muraru, O. Radu, A. Petcu, Apparatus and equipment for determination of soil physical and mechanical characteristics (2015)

11. S. Gorucu, A. Khalilian, J. Han Young, R. Dodd, F. J. Wolak, M. Keskin, Variable Depth Tillage Based on Geo-Referenced Soil Compaction Data in Coastal Plain Region of South Carolina (2001)

12. V. G. Gnilomedov, D. S. Sazonov, M. P. Erzamaev, Justification of traction resistance of a combined plow for longline tillage Bulletin of the Samara State Agricultural Academy 3, 8-13 (2013)

13. V. G. Gnilomedov, A. E. Afonin, M. P. Erzamaev, Energy characteristics of loosening the lower soil layer in longline technologies for its processing Bulletin of Samara State Agricultural Academy 3, 1823 (2011) 